Vol. 18 (2009): 117-128.

\title{
Review article \\ Cryopreservation techniques and their application in vegetatively propagated crop plants in Finland
}

\author{
Anna Nukari ${ }^{*}$, Marjatta Uosukainen ${ }^{1}$, Veli-Matti Rokka², Kristiina Antonius ${ }^{2}$, Qiaochun Wang ${ }^{3}$ \\ and Jari P.T. Valkonen ${ }^{4}$ \\ ${ }^{1}$ MTT Agrifood Research Finland, Plant Production Research, Antinniementie 1, FI-41330 Vihtavuori, Finland, \\ *email: firstname.lastname@mtt.fi \\ ${ }^{2}$ MTT, Biotechnology and Food Research, Myllytie 1, FI-31600 Jokioinen, Finland \\ ${ }^{3}$ Key Laboratory of Genetic Improvement of Horticultural Plants of Northwest China, College of Horticulture, \\ Northwest Agricultural \& Forest University, Yangling 712100, Shaanxi, P.R. China \\ ${ }^{4}$ University of Helsinki, Department of Applied Biology, PO Box 27 (Latokartanonkaari 5), \\ FI-00014 University of Helsinki, Finland
}

\begin{abstract}
Cryopreservation protocols have been introduced as techniques for germplasm preservation of vegetatively propagated horticultural and staple food crops. In Finland, cryopreservation has been studied since 1990's, beginning with cryopreservation of forest tree breeding material and since 2004 on cryopreservation of genetic resources of horticultural plants and potato. Priority was given to cryopreservation of raspberry (Rubus ideaus L.), strawberry (Fragaria x ananassa Duch.) and potato (Solanum tuberosum L.) and the possibility to use cryotherapy in eradication of raspberry bushy dwarf virus (RBDV) from in vitro cultures were studied on raspberry. Modified droplet vitrification cryopreservation protocols were designed for raspberry and strawberry and cryotherapy combined with thermotherapy was proven to be a successful application to eliminate RBDV from infected raspberries. Cryotherapy method can be applied for a large scale elimination of viruses from plant germplasm and from candidate nuclear stock in a certified plant production scheme. Routine use of cryotechniques in germplasm preservation of vegetatively propagated horticultural plants was started. Besides for long term germplasm preservation, cryopreservation techniques can be applied also for maintenance of mother stocks in certified plant production schemes and in commercial plant production. Cryopreservation of potato shoot tips needs additional detailed research to obtain sufficient recovery and regrowth rates.
\end{abstract}

Key-words: cryopreservation, cryotherapy, somatic embryos, raspberries, raspberry bushy dwarf virus, strawberries, potatoes, genetic resources, gene banks, nuclear stock, genetic stability

(C) Agricultural and Food Science

Manuscript received February 2009 
Nukari, A. et al. Cryopreservation of vegetatively propagated Finnish crop plants

\section{Introduction}

Staple food and pollakanthic or perennial horticultural crop species are mostly vegetatively propagated. In field collections, many of these species are susceptible to accumulation of viruses, various other plant pathogens, diverse small genetic mutations, accidental seedlings as well as to abiotic stresses. Due to these risk factors the availability of germplasm and preservation of stock plants in field collections cannot be secured. The establishment of reliable conservation has become an urgent issue. The need of complementary techniques to in vivo conservation of genetic resources has been generally recognized (Engelmann and Engels 2002, Reed et al. 2004).

Over thirty years ago Bajaj and Reinert (1977) reviewed cryotechnology and concluded that cryobiology of plant cell cultures offers a wide range of prospects such as conservation of genetic uniformity, preservation of rare genomes, freeze storage of cell cultures, maintenance of disease free material, cold acclimation and frost resistance, retention of morphogenetic potential and slow metabolism and ageing. Today, cryotechniques are mostly introduced for secondary genetic resource preservation (Reed 2008b). However, these techniques have also potential for wider use in horticultural industry, for instance in certified production scheme and in commercial plant production (Uosukainen et al. 2007).

The aim of the present paper is to give a review of various cryotechniques that can be applied in germplasm conservation and in maintenance of mother stocks of clonally propagated plants, such as strawberry (Fragaria $x$ ananassa Duch.), raspberry (Rubus ideaus L.), potato (Solanum tuberosum L.) and woody species of temperate and boreal zones. Also an overview of cryopreservation research and utilisation of cryotechniques in germplasm preservation and maintenance of certified nuclear stocks of horticultural crop plants in Finland is presented.

Cryopreservation refers to storage of biological samples at ultra low temperatures, for example that one of liquid nitrogen $\left(-196^{\circ} \mathrm{C}\right)$. At ultra-low temperature basically all cellular divisions and metabolic processes cease, and in theory, plant tissues can be stored without any change for an indefinite period of time (Engelmann 1997). Additionally, such storage method requires a small volume, demands very limited maintenance, and is thus relatively cheap (Reed et al. 2004). Interest in cryopreservation techniques awoke from the need of a safe alternative to in vivo plant collections and to develop techniques that could secure plant biodiversity and for the long-term maintenance of genetic resources. Cryopreservation is today used world wide as a safe backup of valuable plant materials and cryopreservation protocols have been established for more than 200 plant species (Engelmann 2004, Wang and Perl 2006, Reed 2008a). Controlled rate cooling, vitrification, encapsulation dehydration and dormant bud preservation have become standard protocols for cryopreservation (Reed 2008b).

Controlled rate cooling method was introduced in 1970's. It is used for both in vitro and in vivo source materials. These techniques are recommended for storing large collections (Reed 2008b). Different stepwise freezing protocols are used together with preculture or acclimation and cryoprotection of samples. During a controlled rate cooling procedure, extracellular ice forms and intracellular water moves to the outside. Formation of extracellular ice reduces the potential ice nucleating inside the cells (Benson 2008a).

In vitrification-based protocols cell solutes are concentrated to a critical viscosity. The liquids become glassy solid and lethal crystalline ice formation will thus be avoided. (Gonzalez-Arnao et al. 2008, Benson 2008a). Development of vitrification-based procedures progressed significantly cryopreservation of organized plant structures (Engelmann 2004, Wang and Perl 2006, GonzalezArnao et al. 2008, Reed 2008a).

Encapsulation of explants in calcium alginate beads was originally introduced as a method to produce synthetic seeds (Redenbaugh et al. 1986). Dehydration is used in combination with encapsulated explants. Dehydration of alginate beads is performed by desiccation under the air of a laminar flow cabinet or in sealed containers with dry silica 
Vol. 18 (2009): 117-128.

gel. When the bead water content is lowered to around $20 \%$, only glass transitions are recorded when samples are plunged in liquid nitrogen (Sherlock et al. 2005).

Besides these standard protocols, also combinations of these methods have been developed together with several modifications for different plants species. Cryopreservation of temperate woody species was started in Japan when Sakai (1960) demonstrated that winter hardy twigs of poplar and willow survived slow cooling and then immersion in liquid nitrogen. Since then this method has been applied and developed further for preservation of dormant buds of fruit species (Sakai and Nishiyama 1978, Tyler and Stushnoff 1988, Towill et al. 2004, Toldam-Andersen et al. 2007, Towill and Ellis 2008). In Finland, studies have been carried out to develop cryopreservation techniques for forest tree breeding materials since 1990's and the method for cryopreservation of dormant buds together with recovery through in vitro culture has been introduced. (Ryynänen 1996, 2000). The dormant bud method together with budding or grafting recovery technique is a good alternative for plants that have poor adaptability to in vitro culture.

Several modifications of the standard protocols have been developed for different plant species. Simple and efficient protocols are necessary for the utility of cryopreservation techniques for a wide range of plant genetic material containing variable genotypes. Such universal techniques could be encapsulation-dehydration (Dereuddre et al. 1990, Fabre and Dereuddre 1990) and droplet vitrification (Panis et al. 2005) as well as encapsulation-vitrication (Matsumoto et al. 1995). At present, droplet vitrification method (Panis et al. 2005) receives much attention. It has been applied in large scale to germplasm collections for banana, potato and garlic (Reed 2008a). Encapsulation-vitrification has been applied to strawberry and potato (Hirai et al. 1998, Hirai and Sakai 1999). Encapsulation-dehydration and encapsulation-vitrification are both applicable methods for raspberry cryopreservation (Wang et al. 2005). Encapsulation-dehydration has also been applied to strawberry (Soria et al. 2007). However, in most plant families these methods need species specific adjustments before they can be applied in large scale conservation of the genetic diversity of the germplasm.

Recently, cryotherapy of shoot tips, an additional application of cryopreservation, has been demonstrated to efficiently eradicate plant pathogens (Wang et al. 2009). In Finland, as a consequence of successful cryopreservation of raspberry nuclear stock and eradication of RBDV from a candidate nuclear stock of a new raspberry cultivar (Wang et al. 2005, 2008b), cryotherapy was introduced to certification scheme of Finnish horticultural plants (Ministry of Agriculture and Forestry 2006) and cryopreservation was applied to maintenance of nuclear stock of strawberries and raspberries (Nukari and Uosukainen 2007, Uosukainen et al. 2007).

\section{Types of plant materials subjected to cryopreservation}

At present, cryopreservation techniques are available for storage of algae, bryophytes, ferns, dedifferentiated cell cultures, embryogenic cultures, excised embryos and embryonic axes, dormant buds, meristem and shoot tips, root tips, pollen and seeds (Benson 2008b, Reed 2008a). Organized plant tissues, such as twigs, dormant buds or in vitro propagated plantlets, proliferating meristem clumps, apical and axillary shoot-tips, shoot tips and nodes and buds, are generally preferred in cryopreservation of vegetatively propagated plants (Panis et al. 2007, Reed 2008a).

Cryopreservation of dormant buds has been adopted as a cryopreservation method for fruit trees in cold climate, where natural cold hardening of buds can be exploited. A standard protocol was developed in North America for dormant apple buds and implemented on large scale in a cold continental climate at the Plant Genetic Resources Unit in Geneva, US (Towill et al. 2004). This method proved to be applicable also to cultivars grown in the milder, Danish maritime winter climate (Toldam-Andersen et al. 2007). This method has been applied also for Pyrus and Ribes as well 


\section{AGRICULTURAL AND FOOD SCIENCE}

Nukari, A. et al. Cryopreservation of vegetatively propagated Finnish crop plants

as other fruit trees and woody ornamentals (Reed 2008a).

Successful cryopreservation requires that the plant tissue survives the storage and is thereafter capable of regenerating into plants (Harding 2004, Reed 2008b). However, there are genotypes that have almost non-existing recovery response after cryopreservation. In case the plant species produce seeds born by apomixes, they can be used in germplasm preservation and also cryopreserved instead of other somatic parts of the plants.

As an alternative to meristematic plant tissues cryopreservation of diverse genotypes as embryogenic cell lines induced from various types of plant organs may be possible. Somatic embryos originating from one plant cell or a group of cells can also be used for development of synthetic seeds (Ipekci and Gozukirmizi 2003) and to create rapid mass propagation systems using bioreactors (Ducos et al. 2008). After successful cryostorage, embryos should germinate and develop into entire plants with homogeneity similar to the true seeds (Tessereau et al. 1994). To produce genetically uniform and stable materials originated from embryogenic clusters was introduced for Citrus species (Sakai et al. 1990). The first examples of successfully cryopreserved plant somatic embryos were originated from Asparagus cladophyll tissue (Uragami et al. 1989). Also embryogenic masses have successfully been preserved in sweet potato (Ipomoea batatas (L.) Lam.) (Blakesley et al. 1996). For certain plants species, such as carrot (Daucus carota L.) and coffee (Coffea arabica L.), somatic embryogenesis has become a routine technique and the economic viability of the method has already been proven (Etienne-Barry et al. 1999). Often embryogenic cell lines are cryopreserved as suspensions, such as in banana (Musa), grapevine (Vitis spp.) and coffee with the maintenance of high regeneration capacity (Panis and Thinh 2001, Wang et al. 2002, 2004).

Cryopreservation of somatic embryos is potentially a method to preserve an increasing range of accessions and genotypes, because different genotypes preserved as shoot tips often show variable regrowth rates. For carrot and coffee, direct regrowth of frozen-thawed somatic embryos has been observed. The size of embryos and the age of the embryogenic strain determined their ability to develop into morphologically normal plantlets (Tessereau et al. 1994). In carrot, even differentiated torpedo shaped embryos, which were $2 \mathrm{~mm}$ in size, survived cryopreservation, but the larger embryos needed a progressive decrease of sucrose content in the medium for successful regeneration (Tessereau et al. 1994). In Finland, the aim is to test various methods to produce somatic embryos from potato cultivars and to cryopreserve the embryogenic clusters developed. Each cryopreserved embryogenic cluster is comprised of high numbers of meristematic regions, which enhances the capacity of cryotechniques. Subsequently, somatic embryos can also be used for development of synthetic seeds, which are cryopreserved, and additionally to create mass propagation systems. Overall, the utilisation of somatic embryogenic cultures for many crop species has various challenges, such as difficulties with germination and rooting, which need to be overcome before the technology can be transferred into practice.

\section{True-to-type evaluation of cryopreserved materials}

Plants regenerated following cryopreservation need to be genetically stable and identical to the original genotypes. The recovery of plant materials from the cryopreservation stages without any intermediate callus formation is essential to avoid somaclonal variation (Gonzales-Arnao et al. 2008). In potato, plants regenerated from cryopreservation did not show abnormalities on their ability to form tubers, but the formation of flowers was impaired compared to the tuber-derived plants (Harding and Benson 1994). Cytological abnormalities or changes at the molecular level were still not observed (Benson et al. 1996, Harding 1997, Harding and Benson 2001). In a few cases, however, plants regenerated after cryopreservation have shown varying levels of genetic changes depending on the species and analysis technique utilised. A recent study carried out on papaya (Carica papaya L.) showed 
Vol. 18 (2009): 117-128.

genotype-dependent variability using various molecular techniques, such as randomly amplified DNA fingerprinting (RAF) and amplified DNA methylation polymorphism (AMP) (Kaity et al. 2008). In hops (Humulus lupulus L.), however, no genetic changes using RAPD (randomly amplified DNA polymorphism) and amplified fragment length polymorphism (AFLP) techniques were detected, but some epigenetic changes with methylation sensitive amplified polymorphism (MSAP) were found dependent on the cryopreservation protocol used (Peredo et al. 2008). These findings suggest that more specific molecular analysis techniques for genetic stability will be needed to test true-to-type status of the cryopreserved materials.

\section{Cryotherapy for pathogen eradication}

Cryotechniques can have potential use as a substitute or complement to classical virus eradication techniques such as meristem culture and thermotherapy (Wang and Valkonen 2008a, 2008b). Experiments performed with plum shoot tips (Brison et al. 1997), banana meristematic cultures (Helliot et al. 2002) and grape shoot tips (Wang et al. 2003) showed various degrees of elimination of different viruses after freezing of infected viruses. The development of this technique improves plant health and the quality of culture, storage and exchange of germplasm ( Reed et al. 2004).

Adequate management measures should be taken by the genebank to eliminate infection and contamination (Engels and Visser 2003). This requirement is congruent with the certified production schemes for horticultural crops presented by European and Mediterranean Plant Protection Organization (OEPP/EPPO) (1993). Cryotherapy is potential means for the establishment of high quality long term preservation of selected germplasm as well as for establishment of nuclear stock. The maintenance of plant health is secured when materials are subsequently transferred to long-term preservation conditions using available cryotechniques (Uosukainen et al. 2007, Wang et al. 2009).
Tissue culture-based virus eradication methods were introduced in Finland in the 1970's when in vitro techniques were utilised for production of virus-free potato clones (Tapio 1972) and subsequently for currants, gooseberry, raspberry and strawberry (Bremer and Ylimäki 1978, Uosukainen and Kurppa 1988). Recently, also cryotherapy has been successfully applied for the elimination of plant viruses and phytoplasmas from plant materials (Wang and Valkonen 2007, 2008b, Wang et al. 2008). Cryotherapy of shoot tips has been suggested a novel technique for pathogen eradication, much more efficient than the traditional methods like meristem tip culture (Wang et al. 2009).

In cryopreservation, the main focus lays on conserving high numbers of plant materials using techniques in which the tissue survival rate after thawing is maximised. On the contrary, for pathogen eradication by cryotherapy, it is essential that viability of only the meristematic, uninfected cells is ensured and the highly vacuolated, often infected cells are killed, thereby producing healthy shoots (Wang et al. 2008, 2009). Combination of cryotherapy with a preceding thermotherapy stage was found to be the solution to eliminate RBDV from an infected raspberry clone; the procedure which had earlier been practically impossible using the traditional methods (Wang et al. 2008). Similarly, potato leaf roll virus (PLRV) and potato virus Y (PVY) were also efficiently eliminated by cryotherapy from potato clones (Wang et al. 2006). Professor Qiaochun Wang has studied the mechanisms of virus eradication from the meristematic shoot tips and has together with his associates given a comprehensive overview on eradication of pathogens, including viruses, phytoplasmas and bacteria (Wang and Valkonen 2007,2008a, 2008b, Wang et al. 2009).

\section{Cryopreservation of crop plants in Finland}

In 1990's, cryopreservation research was started in Finland as an aim to preserve forest tree breeding material by using dormant buds (Ryynänen 1996). 


\section{AGRICULTURAL AND FOOD SCIENCE}

Nukari, A. et al. Cryopreservation of vegetatively propagated Finnish crop plants

In 2004 MTT Plant Production Research, Laukaa (MTT Laukaa) initiated a major research project for establishment of cryopreservation methods for vegetatively propagated horticultural plants. MTT plant genetic resource working groups, sub-coordinated under the Finnish national genetic resource programme, proposed cryopreservation as the first backup method for the long-term preservation of vegetatively propagated, selected genotypes. The priority was given to species for which a cryopreservation procedure is already available (Aaltonen et al. 2006a, 2006b, Ahokas et al. 2006), such as for raspberry.

The cryopreservation project of vegetatively propagated horticultural plants was based on the pathogen free in vitro material which was available in the Finnish nuclear stock bank. The work was started by screening different cryopreservation methods. Later also various explant sources for cryopreservation has been evaluated, such as in vitro grown meristematic tissues, shoot tips, dormant buds, embryogenic clusters or somatic embryos. In the cryopreservation of in vitro materials, apical shoot meristem tips or basal buds were used as explants, rather than merely meristematic tissue.

At the University of Helsinki, Wang et al. (2005) introduced an application of encapsulation-vitrification and encapsulation-dehydration cryopreservation protocols to raspberry shoot tips excised from in vitro plantlets. Further studies and development of the protocols at MTT Laukaa proved encapsulation-vitrification and droplet vitrification methods successful basic techniques for cryopreservation of micropropagated raspberry shoot tips. A modified droplet vitrification method was designed for conservation of raspberries and also for other vegetatively propagated horticultural plants, such as strawberry (Nukari et al. 2006).

Cryopreservation experiments of dormant buds were carried out by using traditional twostep freezing method with a controlled rate freezer or cryopreservation of naturally hardened buds by using slow freezing to $-20{ }^{\circ} \mathrm{C}\left(2{ }^{\circ} \mathrm{C} /\right.$ hour $)$ with a combined refrigerator-freezer or cryopreservation of naturally hardened buds collected from minus degrees and stored in freezer in $-25^{\circ} \mathrm{C}$. Also different strategies to promote regrowth of apple
(Malus domestica Borkh.), sour cherry (Prunus cerasus L.), plum (Prunus domestica L.), black currant (Ribes nigrum L.) and red currant (Ribes Rubrum-group L.) were tested. Freeze-drying at $-4{ }^{\circ} \mathrm{C}$ was occasionally used as a pre-treatment for the dormant buds in the two step freezing method. For recovery, both chip bud grafting using T-cut in rootstock and initiating in vitro cultures from the cryopreserved buds were used.

The use of cryopreservation techniques for dormant buds of plum, apple, black currant and red currant was not successful when it was combined with chip bud grafting. Instead of the bud grafting, establishment of in vitro cultures from cryopreserved buds gave more promising recovery results especially for sour cherry. However, the recovery success rates in plum and apple buds were still low. Only a few buds showed regrowth on an agar-gelled medium (Table 1). The main reasons for the failure were microbes that contaminated the cultures when the transplants were excised from cryopreserved dormant buds collected from the field. Cryopreservation of in vitro cultures is often preferred to in vivo dormant buds, because the contamination risks induced by the explants can be thereby mainly avoided. In case of grafting contamination is not an issue.

In 2006, the work was extended to potato, in collaboration with MTT Biotechnology and Food Research. The aim was to apply cryopreservation techniques for the long-term genetic resource preservation of vegetatively propagated plants of importance in Finland. Cryopreservation of strawberry and potato were studied for both meristematic shoot tips and lateral buds derived from in vitro cultures. At MTT, droplet vitrification method was chosen as the most suitable cryopreservation procedure applicable for a wide range of vegetatively propagated horticultural species and their various genotypes.

The cryopreservation genebank was established at MTT Laukaa in 2006. A protocol to utilise cryopreservation in the certification scheme of nuclear stock and in the maintenance and propagation of propagation stocks was developed by MTT Laukaa (Uosukainen and Laamanen 2006, Uosukainen et al. 2007). Cryopreservation was accepted as a 
Vol. 18 (2009): 117-128.

Table 1. The survival and recovery rates after cryopreservation of dormant buds collected from field. The buds were immersed into liquid nitrogen from $-25^{\circ} \mathrm{C}$ in cryotubes. After thawing the meristems were isolated under stereo-microscope and cultured on agar gelled medium. Survival rate was counted from number of buds being visually green two months after thawing and recovery rate of buds was counted from number of buds, that recovered into in vitro cultures.

\begin{tabular}{llcrc}
\hline Plant species & Cultivar & $\begin{array}{c}\text { Number of batches col- } \\
\text { lected at different times } \\
(7-12 \text { buds in each) }\end{array}$ & $\begin{array}{c}\text { Survival rate } \\
\text { of buds at 2 } \\
\text { months }(\%)\end{array}$ & $\begin{array}{c}\text { Recovery rate } \\
\text { of buds }(\%)\end{array}$ \\
\hline Plum (Prunus domestica) & 'Kuokkala' & 4 & 0 & 0 \\
Plum (Prunus domestica) & 'Sinikka' & 4 & 10 & 0 \\
Apple (Malus domestica) & 'Pirja' & 4 & 21 & 0 \\
Sour Cherry (Prunus cerasus) & 'Sikkolan Kuulasmarja' & 6 & 55 & 30 \\
\hline
\end{tabular}

preservation method of the nuclear stock collection by the Ministry of Agriculture and Forestry and this application was included into the statute of the Finnish certification scheme (Ministry of Agriculture and Forestry 2006, Uosukainen et al. 2007). Cryo-collections of the nationally valuable raspberry and strawberry accessions were initiated (Nukari and Uosukainen 2007, Uosukainen et al. 2007). The prerequisites to establish cryo-collections of other vegetatively propagated horticultural genera such as Ribes, Prunus, Malus, Rosa, Dasiphora and Syringa were also developed, as the same equipments and protocols can be exploited. By the end of 2008 altogether 29 Rubus accessions, 8 Fragaria accessions, 9 Humulus accessions, 1 Ribes accession and 1 Syringa accession were taken into long-term cryopreservation in the Laukaa cryobank.

At MTT Biotechnology and Food Research, Jokioinen, preliminary studies to produce somatic embryos from cultivated potato clones and raspberry clones were also carried out. In potato, the applied somatic embryogenesis protocol followed the previously published methods of Seabrook and Douglass (2001) and Sharma and Millam (2004). Somatic embryogenesis was induced using internodes, leaf laminae and petioles of in vitro grown potato varieties Bintje, Fambo, Idole, Kardal, Matilda, Nicola, Pito, Saturna, Timo and Van Gogh. Nodular callus and embryo-like structures were formed and entire plants were subsequently regenerated. The plant materials are currently used for true-to-type status analyses using previously developed molecular analysis techniques as described by Antonius et al. (2008).

Preliminary experiments were also carried out at MTT Laukaa to cryopreserve embryogenic clusters of potato using the encapsulation-vitrification technique. However, the first experiences demonstrated that additional detailed research will be needed to obtain sufficient recovery and regrowth rates.

In collaboration with University of Helsinki and MTT Laukaa, cryotherapy combined with thermotherapy was used as a novel strategy to eradicate a pollen-born virus, RBDV, from the infected raspberry clone Z13 (Wang et al. 2008). The persisting virus infection had prevented MTT from releasing this promising raspberry breeding line for cultivation. This new procedure of combined thermotherapy and cryotherapy, will be helpful not only in virus eradication from raspberry but also with other virus-host combinations in which virus elimination is a rather complex procedure. Consequently, Finland has become a forerunner in the use of the cryotherapy to eliminate diseases from crop plant materials.

Investments for establishment of cryopreservation laboratory depend on the local infrastructure. In Finland cryolaboratory was integrated to the existing tissue culture laboratory which is in charge of establishment, maintenance and disease testing of the horticultural nuclear stock. Plant material for cryopreservation was mostly harvested from in 
Nukari, A. et al. Cryopreservation of vegetatively propagated Finnish crop plants

vitro cultures. Therefore only small alteration in facilities was needed. The most expensive investment was the cryotank (model 1520 ETERNE). In 2006 , the total costs of establishment of cryofacility were $20000 €$ including the price of the equipment, installing and training for users.

During transfer of the material to cryopreservation, expenses comprised mostly from labour costs. The amount of working hours depended on the plant material and how experienced the person was to process the plant material in question. Transfer of material from micropropagation to cryotank costs about 240-400 €/accession (an accession is 10 cryotubes). Total costs, including establishment of meristem cultures, multiplication of material for cryopreservation, transfer of the material to the cryotank and the quality control, were around $1000 € /$ accession (10 cryotubes). At delivery, including recovery procedures, post culture and materials, the costs were about $200 € /$ accession.

During the long term storage variable costs comprised mostly from liquid nitrogen. In Finland, the annual cost for keeping up one tank for 30000 cryotubes was 4500 euro /in 2008 which was about 1,5 euro/accession. Total annual costs including overall costs in long term preservation will be less than $5 € /$ accession.

Cryopreservation is considered a cost effective method for long term preservation of plant material. However, as Benson (2008b) pointed out, there are very limited numbers of economic efficiency models for plant cryopreservation. The studies that have been undertaken are difficult to compare, but the estimations have been in favour of cryopreservation in comparison with field-maintenance. Cost effectiveness may be limited by labour, consumable and overall costs as well as by poor recovery response of plant material. Some genotypes may survive the cryogenic storage stage but do not regrow afterwards. Therefore poor survival is often compensated by cryopreserving a greater number of plant units/ vial (Reed 2008b).

As long term cryobanks are established, it is important to study the effects of cryopreservation and banking strategies on longevity of stored material. The actual timescale for changes in viability of plant material has yet to be calculated (Benson 2008b).

Cryopreservation can be taken as a tool of maintaining the propagation stocks in commercial plant production (Uosukainen et al. 2007). For animal breeding and human medicine cryogenic methods have already practical applications. For plant tissues, cryotechniques has been studied mainly as a tool for the long term preservation of germplasm. However, also in commercial plant production, this method could be applicable. Cryopreservation is to a large degree based on in vitro techniques, which already is applied in horticultural industry. Meristem culture in vitro was first applied in certified production scheme during the nuclear stock production stage (Reinert and Bajaj 1977) and today it is applied in commercial production of horticultural plants world wide. Cryotherapy and cryopreservation of disease-free nuclear stock have already been introduced to certified production scheme in Finland (Uosukainen et al. 2007). Equal to germplasm preservation, the maintenance of true to type and high quality mother stock material in vivo is expensive in commercial production. Combination of in vitro culture and cryopreservation could be an economically lucrative solution because cryopreservation allows maintenance of a more extensive selection of mother stocks than in vivo methods and flexibility in establishing of large scale production whenever it is needed.

One major advantages of cryostorage is the cessation of ageing process of crypreserved cells. When the mother stock of a new cultivar is cryopreserved, the original propagation material can always be restored to production. Because the number of successive subcultures or clonal progation generations does not increase, also the risk of somaclonal variation is minimized. In traditional, long term clonal propagation procedures, generation after generation, diverse gene mutations accumulate and little by little the material in production will be declined. In cryopreservation, mother stock does not decline. This is also an advantage in long term preservation of germplasm.

Germplasm health inspection, disease and pest indexing and elimination procedures should always be included in the establishment of germplasm col- 
Vol. 18 (2009): 117-128.

lections. (Benson 2008b, Reed 2008b, Wang et al. 2009). This can be accomplished cost-effectively by combining meristem culture and in vitro preservation with cryotherapy and cryopreservation and by utilizing the expertise and facilities of the institutes that execute the national certification scheme of vegetatively propagated crops. The preliminary estimated costs of long-term cryopreservation at MTT Laukaa are correspondent with the earlier observations. Application of cryotechniques to preservation of valuable germplasm as well as to maintenance of nuclear stocks makes the cooperation between nuclear stock banks and gene banks simple. Once plant material is tested to be diseasefree, it can be stored to cryobank, utilised in production and eventually transferred to genebank as a high quality germplasm material that can be safely transported from one country to another without any risk of spreading diseases.

\section{Conclusions}

As a conclusion, the methods introduced in the recent years are well complementary to each other and can be applied to the preservation and utilisation of genetic resources (Nukari and Uosukainen 2007, Wang et al. 2009). The basic cryopreservation methods like encapsulation and vitrification protocols are quite practical and effective although the encapsulation-based techniques have been more suitable for specific purposes like cryotherapy or cryopreservation of somatic embryos.

The potential of cryopreservation for elimination of viruses from infected plants as a substitute or complement to classical virus eradication techniques such as meristem culture and cryotherapy should be further explored. However, there are still certain limits in the techniques such as low recovery rates, which may be seen as one of the main challenges for future research in cryopreservation. Continuing development of tissue culture and cryopreservation systems and techniques to evaluate genetic stability will make it more fea- sible to determine the possible genetic changes in plant material.

Acknowledgements. The authors would like to acknowledge Dr. Steve Millam, Chichester College, Department of Horticulture, Chichester, UK, for the critical review of the manuscript. We express our gratitude for scientific support to Marja-Leena Manninen, Kirsti Mäkelä, Saija Rantala, Teija Tenhola-Roininen, Tuija Aronen, Alena Gajdošová, the guidance group members of the Finnish research project, Tuula Pehu, Paula Elomaa, Aarne Kurppa, JukkaPekka Palohuhta, Mari Rusanen and Leena Ryynänen and for financial support to the Ministry of Agriculture and Forestry of Finland and the National Plant Genetic Resources Programme of Finland.

\section{References}

Aaltonen M., Antonius K., Hietaranta T., Karhu S., Kinnanen H., Kivijärvi P., Nukari A., Sahramaa M., Tahvonen R. \& Uosukainen M., 2006a. Guidelines for long-term preservation of Finnish plant genetic resources. Fruits and berries. (In Finnish with an English abstract). Maa ja elintarviketalous/Kasvintuotanto (Agrifood Research Finland/ Plant Production) no. 89. Jokioinen, 158 p. Available on the Internet: http://www.mtt.fi/met/pdf/met89.pdf.

Aaltonen, M., Antonius, K., Juhanoja, S., Järvelin, V., Laamanen, J., Nukari, A., Peräinen, R., Sahramaa, M., Uosukainen, M. \& Uusitalo, M. 2006b. Guidelines for longterm preservation of Finnish plant genetic resources. Woody ornamentals. (In Finnish with an English abstract). Maa- ja elintarviketalous/Kasvintuotanto (Agrifood Research Finland/Plant Production) no. 91. Jokioinen, 253 p. Available on the Internet: http://www.mtt.fi/ met/pdf/met91.pdf.

Ahokas H., Galambosi B., Kairikko H., Kallela M., Sahramaa M., Suojala-Ahlfors T., Valo R. \& Veteläinen M., 2006. Guidelines for long-term preservation of Finnish plant genetic resources, Vegetables, herbs and medicinal plants. (In Finnish with an English abstract). Maa ja elintarviketalous/Kasvintuotanto (Agrifood Research Finland/ Plant Production) no. 85. Jokioinen, 99 p. Available on the Internet: http://www.mtt.fi/met/ pdf/met85.pdf.

Antonius, K., Rokka, V-M., Tenhola-Roininen, T., Gajdošová, A., Kalendar, R. \& Schulman, A. 2008. Monitoring clonal stability with retrotransposon-based markers. In: Laamanen, J., Uosukainen, M., Häggmann, H., Nukari, A. \& Rantala, S. (eds.). Cryopreservation of crop species in Europe. CRYOPLANET - COST Action 871. February $20^{\text {th }}-23^{\text {rd }} 2008$, Oulu, Finland. Agrifood Research Working Papers 153: 49.

Bajaj, Y.P.S. and Reinert, J. 1977. Cryobiology of plant cell cultures and establishment of gene-banks. In: Reinert, J. \& Bajaj, Y.P.S. (eds.). Applied Fundamental Aspects of 


\section{Nukari, A. et al. Cryopreservation of vegetatively propagated Finnish crop plants}

Plant Cell, Tissue, and Organ Culture. Springer Verlag, Berlin, Heidelberg, New York. p. 756-777.

Benson, E.E. 2008a. Cryopreservation theory. In: Reed, B.M. (ed.). Plant Cryopreservation: A Practical Guide. Springer Science+Business Media, LLC, New York. p. 15-32.

Benson, E.E. 2008b. Cryopreservation of phytodiversity: A critical appraisal of theory \& practice. Critical Reviews in Plant Sciences 27: 141-219.

Benson, E.E., Wilkinson, M., Todd, A., Ekuere, U. \& Lyon, J. 1996. Developmental competence and ploidy stability in plants regenerated from cryopreserved potato shoottips. CryoLetters 17: 119-128.

Blakesley, D., Al Mazrooei, S., Bhatti, M.H. \& Henshaw, G.G. 1996. Cryopreservation of non-encapsulated embryogenic tissue of sweet potato (Ipomoea batatas). Plant Cell Reports 15: 873-876.

Bremer, K. \& Ylimäki, A. 1978. A certificate system to produce and distribute virus tested propagation material from berry plants in Finland. Annales Agriculturae Fenniae 17: 42-44.

Brison, M., de Boucaud, M.T., Pierronnet, A. \& Dosba, F. 1997. Effect of cryopreservation on the sanitary state of a cv. Prunus rootstock experimentally contaminated with plum pox potyvirus. Plant Science 123: 189-196.

Dereuddre, J., Scottez, C., Arnaud, Y. \& Duron, M. 1990. Resistance of alginate-coated axillary shoot tips of pear tree (Pyrus communis L. vv. Beurre Hardy) in vitro plantlets to dehydration and subsequent freezing in liquid nitrogen. Comptes Rendus de l'Académie Sciences, Serie III. Sciences de la Vie, Paris 310: 317-323.

Ducos, J.P., Terrier, B., Courtois, D. \& Pétiard, V. 2008. Improvement of plastic-based disposable bioreactors for plant science needs. Phytochemistry Reviews 7: 607613. Available on the Internet: Doi: $10.1007 /$ s11101008-9089-1

Engelmann, F. 1997. In vitro conservation methods: In: Callow, J.A., Ford-Lloyd, B.V. \& Newbury, H.J. (eds.). Biotechnology and plant genetic resources. CAB International, Oxford, pp. 119-161.

Engelmann, F. \& Engels, J.M.M. 2002. Technologies and strategies for ex situ conservation. In: Engels, J.M.M., Rao, V.R., Brown, A.H.D. \& Jackson, M.T. (eds.). Managing Plant Genetic Diversity. CAB International, Wallingford, UK/International Plant Genetic Resources Institute, Rome, Italy. p. 89-104.

Engelmann, F. 2004. Plant cryopreservation: progress and prospects. In vitro Cellular and Developmental Biology Plant 40: 427-433.

Engels, J. \& Visser, B. 2003. Genebank management procedures. In: Engels, J.M.M. \& Visser, L. (eds.). A guide to effective management of germplasm collections. IPGRI Handbooks for Genebanks No. 6. IPGRI, Rome, Italy. p. 60-79.

Etienne-Barry D, Bertrand B, Vasquez N, Etienne H. 1999. Direct sowing of Coffea arabica somatic embryos massproduced in a bioreactor and regeneration of plants. Plant Cell Reports 19: 111-117.

Fabré, J. \& Dereuddre, J. 1990. Encapsulation-dehydration: a new approach to cryopreservation of Solanum shoot-tips. CryoLetters 11: 413-426.

Gonzalez-Arnao, M., Panta, A., Roca, W.M., Escobar, R.H. \& Engelmann, F. 2008. Development and large scale ap- plication of cryopreservation techniques for shoot and somatic embryo cultures of tropical crops. Plant Cell Tissue and Organ Culture 92: 1-13.

Harding, K. 1997. Stability of the ribosomal RNA genes in Solanum tuberosum L. plants recovered from cryopreservation. CryoLetters 18: 217-230.

Harding, K. 2004. Genetic integrity of cryopreserved plant cells: a review. CryoLetters 25: 3-22.

Harding, K., Benson, E.E. 1994. A study of growth, flowering, and tuberisation in plants derived from cryopreserved potato shoot-tips: implications for in vitro germplasm collections. CryoLetters 15: 59-66.

Harding, K., Benson, E.E. 2001. The use of microsatellite analysis in Solanum tuberosum L. in vtro plantlets derived from cryopreserved germplasm. CryoLetters 22: 199-208.

Helliot, B., Panis, B., Poumay, Y., Swennen, R., Lepoivre, P. \& Frison, E. 2002. Cryopreservation for the elimination of cucumber mosaic and banana streak viruses from banana (Musa ssp.). Plant Cell Reports20:1117-1122.

Hirai, D. \& Sakai, A. 1999. Cryopreservation of in vitrogrown meristems of potato (Solanum tuberosum L.) by encapsulation-vitrification. Potato Research 42: 153-160.

Hirai, D., Shirai, K. Shirai, S. \& Sakai, A. 1998. Cryopreservation on in vitro-grown meristems of strawberry (Fragaria $\mathrm{x}$ ananassa Duch.) by encapsulation- vitrification. Euphytica 101: 109-115.

Ipekci, Z. \& Gozukirmizi, N. 2003. Direct somatic embryogenesis and synthetic seed production from Paulownia elongata. Plant Cell Reports 22: 16-24. Available on the Internet: Doi: 10.1007/s00299-003-0650-5

Kaity, A., Ashmore, S.E., Drew, R.A., Dulloo, M.E. 2008. Assessment of genetic and epigenetic changes following cryopreservation in papaya. Plant Cell Reports 27: 1529-1539.

Matsumoto, T., Sakai, A. \&Yamada, K. 1994. Cryopreservation of in vitro grown apical apical meristems of wasabi (Wasabia japonica) by vitrification and subsequent high plant regeneration. Plant Cell Reports 13: 442-446.

Ministry of Agriculture and Forestry 2006. The statute of the Ministry of Agriculture and Forestry on certified propagation and plant material. Asetus 6/2006. (In Finnish). Ministry of Agriculture and Forestry. MMM, Tietopalvelukeskus, Helsinki. 39 p. Available on the Internet: http:// www.finlex.fi/pdf/normit/25058-06009fi.pdf

Nukari, A., Uosukainen, M. \& Flyktman, A. 2006. Cryopreservation of strawberry. NJF Report 2/2006: 10.

Nukari, A. \& Uosukainen, M. 2007. Cryopreservation in the Finnish national germplasm programme for horticultural plants. Advances in Horticultural Science 21: 232-234.

OEPP/EPPO 1993. Certification schemes. PM4/7 Nursery requirements - recommended requirements for establishments participating in certification of fruit or ornamental crops. Bulletin OEPP/EPPO Bulletin 23: 249-252.

Panis, B., Piette, B. \& Swennen, R. 2005. Droplet vitrification of apical meristems: A cryopreservation protocol applicable to all Musaceae. Plant Science 168: 45-55.

Panis, B., Van den Houwe, I., Piette, B. \& Swennen, R. 2007. Cryopreservation of the banana germplasm collection at the internationala Transit Centre - Biodiversity International. Advances in Horticultural Science 
Vol. 18 (2009): 117-128.

21: $235-238$

Panis, B. \& Thinh, N.T. 2001. Cryopreservation of Musa germplasm. In: Escalkat, J.V. \& Sharrock, S. (eds.). INIBAP Technical Guideline 5. International Network for the Improvement of Banana and Plantain, Montpellier. $44 \mathrm{p}$.

Peredo, E.L., Arroyo-Garcia, R., Reed, B.M. \& Angeles Revilla, M. 2008. Genetic and epigenetic stability of cryopreserved and cold-stored hops (Humulus lupulus L.). Cryobiology 57: 234-241.

Redenbaugh, K., Paasch, B.D., Nichol, J.W., Kossler, M.E., Viss, P.R., \& Walker, K.A. 1986. Somatic seeds: Encapsulation of asexual plant embryos. Biotechnology 4: 797-801.

Reed, B.M., Engelmann, F., Dulloo, M.E. \& Engels, J.M.M. 2004. Technical Guidelines on management of field and in vitro germplasm collections. Handbooks for genebanks No. 7, IPGRI, Rome, Italy. 106 p.

Reed, B.M. (ed.). 2008a. Plant Cryopreservation: A Practical Guide. Springer Science+Business Media, LLC, New York. p. 3-13.

Reed, B.M. 2008b. Cryopreservation - Practical Considerations. In: Reed, B.M. (ed.). Plant Cryopreservation: A Practical Guide. Springer Science+Business Media, LLC, New York. p. 3-13.

Reinert, J. \& Bajaj, Y.P.S. (eds.) 1977. Applied Fundamental Aspects of Plant Cell, Tissue, and Organ Culture. Springer Verlag, Berlin, Heidelberg, New York. 803 p.

Ryynänen, L. 1996. Survival and regeneration of dormant silver birch buds stored at superlow temperatures. Canadian Journal of Forest Research 26: 617-623.

Ryynänen, L. 2000. Birch genes can be preserved at a super-low temperature. Forest Research 2b: 12-13.

Sakai, A. 1960. Survival of the twigs of woody plants at $-196{ }^{\circ} \mathrm{C}$. Nature 185: 392-394.

Sakai, A. \& Nishiyama, Y. 1978. Cryopreservation of winter vegetative buds of hardy fruit trees in liquid nitrogen. HortScience 13: 225-227.

Sakai, A., Kobayashi, S. \& Oiyama, I. 1990. Cryopreservation of nucellar cells of navel orange (Citrus sinensis Osb. var. brasiliensis Tanaka) by vitrification. Plant Cell Reports 9: 30-33.

Seabrook, J.E.A. \& Douglass, L.K. 2001. Somatic embryogenesis in various potato tissues from a range of genotypes and ploidy levels. Plant Cell Reports 20: 175-182.

Sharma, S.K. \& Millam, S. 2004. Somatic embryogenesis in Solanum tuberosum L.: a histological examination of key developmental stages. Plant Cell Reports 23: 115-119.

Sherlock, G., Block, W. \& Benson, E.E. 2005. Thermal analysis of the plant encapsulation-dehydration cryopreservation protocol using silca gel as the desiccant. CryoLetters 26: 45-54.

Soria, C., Gálvez-Farfán, J., Ariza, M.T., Medina, J.J. \& Gonzalez-Benito, M.E. 2007. Implementing a strawberry cryogenic genebank: a comparison in agronomic traits of plants derived from cryopreserved apices, in micropropagation, and conventional propagation. Advances in Horticultural Science 21: 207-210.

Tapio, E. 1972. Virus-free clones on the potato varieties Pito and Tammiston Aikainen. Annales Agriculturae Fenniae 11: 115-118.
Tessereau, H., Florin, B., Meschine, M.C., Thierry, C. \& Pétiard, V. 1994. Cryopreservation of somatic embryos: A tool for germplasm storage and commercial delivery of selected plants. Annals of Botany 74: 547-555.

Toldam-Andersen, T.B., Nygaard, T.B. \& Krogholm, K.S. 2007. Cryopreservation of dormant buds of apple cultivars in a mild maritime winter climate. Advances in Horticultural Science 21: 193-197.

Towill, L.E., Forsline, P.L., Walters, C., Waddell, J.W. \& Laufmann, J. 2004. Cryopreservation of Malus germplasm using a winter vegetative bud method: results from 1915 accessions. CryoLetters 25: 323-334.

Towill, L.E. \& Ellis, D.D. 2008. Cryopreservation of dormant buds. In: Reed, B.M. (ed.). Plant Cryopreservation: A Practical Guide. Springer Science+Business Media, LLC, New York. p. 421-443.

Tyler, N. \& Stushnoff, C., 1988. Dehydration of dormant apple buds at different stages of cold acclimation to induce cryopreservability in different cultivars. Canadian Journal of Plant Science 68: 1169-1176.

Uragami, A., Sakai, A., Nagai, M. \& Takahashi, T. 1989. Survival of cultured cells and somatic embryos of Asparagus officinalis cryopreserved by vitrification. Plant Cell Reports 8: 418-421.

Uosukainen, M. \& Kurppa, A. 1988. Production of healthy planting material. Annales Agriculturae Fenniae 27: 209-218.

Uosukainen, M. \& Laamanen, J. 2006. Cryopreservation a new tool in production and maintenance of strawberry nuclear stock. NJF Report 2(2006): 10.

Uosukainen, M., Laamanen, J. \& Nukari, A. 2007. Cryopreservation in certified plant production. Advances in Horticultural Science 21: 258-260.

Wang, Q.C., Cuellar, W., Rajamäki, M.L., Hirata, Y. \& Valkonen, J.P.T. 2008. Combined thermotherapy and cryotherapy for virus eradication: relation of virus distribution, subcellular changes, cell survival and viral RNA degradation in shoot tips to efficient production of virus-free plants. Molecular Plant Pathology 9: 237-250. Available on the Internet: Doi: 10.1111/j.13643703.2007.00456.x

Wang, Q.C., Gafny, R., Sahar, N., Sela, I., Mawassi, M., Tanne, E. \& Perl, A. 2002. Cryopreservation of grapevine (Vitis vinifera L.) embryogenic cell suspensions by encapsulation-dehydration and subsequent plant regeneration. Plant Science 162 (2002): 551-558.

Wang, Q.C., Laamanen, J., Uosukainen, M. \& Valkonen, J.P.T. 2005. Cryopreservation of in vitro-grown shoot tips of raspberry (Rubus idaeus L.) by encapsulationvitrification and encapsulation-dehydration. Plant Cell Reports 24: 280-288. Available on the Internet: Doi: 10.1007/s00299-005-0936-x

Wang, Q.C., Liu Y., Xie Y. \& You M. 2006. Cryotherapy of potato shoot tips for efficient elimination of Potato leaf roll virus (PLRV) and Potato virus Y (PVY). Potato Research 49: 119-129.

Wang, Q.C., Mawassi, M., Li, P., Grafny, R., Sela, I.. \& Tanne, E. 2003. Elimination of grapevine virus A (GVA) by cryopreservation of in vitro grown shoot tips of Vitis vinifera L. Plant Science 165: 321-327.

Wang, Q.C., Mawassi, M., Sahar, N., Li, P., Violeta, C.T., Gafny, R., Sela, I., Tanne, E \& Perl, A. 2004. Cryopreservation of grapevine (Vitis spp.) embryogenic cell 


\section{AGRICULTURAL AND FOOD SCIENCE}

Nukari, A. et al. Cryopreservation of vegetatively propagated Finnish crop plants

suspensions by encapsulation-vitrification. Plant Cell, Tissue and Organ Culture 77: 267-275.

Wang, Q.C., Panis, B., Engelmann, F., Lambardi, M. \& Valkonen, J.P.T. 2009. Cryotherapy of shoot tips: a technique for pathogen eradication to produce healthy planting material and for cryopreservation of healthy plant genetic resources. Annals of Applied Biology 154, in press. Available on the Internet: Doi: 10.1111/j.17447348.2008.00308.x

Wang Q.C. \& Perl A. 2006. Cryopreservation in Floricultural Plants. In: Teixeira da Silva, J.A. (eds.). Floriculture, Ornamental and Plant Biotechnology: Advances and Topical Issues. Global Science Books, Isleworth,
UK. p. 524-539.

Wang, Q.C. \& Valkonen, J.P.T. 2007. Elimination of viruses and phytoplasma by cryotherapy of in vitro-grown shoot tips. Analysis of all cases. Advances in Horticultural Science 21: 265-269.

Wang, Q.C. \& Valkonen, J.P.T. 2008a. Efficient elimination of sweet potato little leaf phytoplasma from sweetpotato by cryotherapy of in vitro grown shoot tips. Plant Pathology 57: 338-347. Available on the Internet: Doi: 10.1111/j.1365-3059.2007.01710.x

Wang, Q.C. \& Valkonen, J.P.T. 2008b. Cryotherapy of shoot tips: novel pathogen eradication method. Trends in Plant Science 14: 119-122. 